\title{
How Down is a Downbeat? Feeling Meter and Gravity in Music and Dance
}

\author{
JONATHAN STILL \\ Institute of Education, London, UK
}

\begin{abstract}
The idea that metrical accent might be related to an embodied sense of "up" and "down" is implied by the terms "upbeat" and "downbeat," and is central to theories of meter as gravitational field, such as those evolved by Robert Hatten and Steve Larson. Yet as Hatten himself notes, upbeats and downbeats do not always map conveniently on to upward or downward movements in dance. Drawing on ethnographic research among trainee ballet teachers and recent theories of musical meter, this article discusses some practical and theoretical problems that arise when trying to teach about meter in the context of ballet training. It is suggested that empathic listening and perspective taking, rather than appeals to common embodied experiences of meter, may be key to developing better interdisciplinary understanding between musicians and dancers.
\end{abstract}

Submitted 2014 June 23; accepted 2014 June 29.

KEYWORDS: meter, rhythm, ballet, music pedagogy, empathy

\section{INTRODUCTION}

IN the training of ballet teachers, meter and time signature are conventionally considered the most basic musical categories to consider when constructing an exercise in a ballet class: is it going to be "in three" or "in two"? Yet in my experience as a teacher of music to trainee ballet teachers, and an accompanist for ballet classes, these apparently rudimentary topics can present problems, even for ballet teachers who have some prior musical knowledge or training. To some extent, this reflects the nature of the subject. In "music theory" in the sense of the basics of Western music notation, time signature is presented as a simple, objective fact of music, but in "music theory" in the sense of research and speculation about the perception and cognition of meter, or scholarly writing about relationships between the theory, notation and performance of meter, it is clearly not that simple at all (e.g. Hasty, 1997; Houle, 1987; London, 2012; Mirka, 2009; Rothstein, 2008). With this in mind, and given that moving is what dancers do best, I have tried to use movement as a means of teaching meter, particularly in the light of recent interest in embodied music cognition, and speculation about why and how we sense motion in music (Clarke, 2005; Larson, 2012; Hatten, 2004; Cox, 2011; Eitan \& Granot, 2006; Iyer, 2002; Leman, 2008; Toiviainen, Luck, \& Thompson, 2010).

In what follows, I first explain why meter and time signature are both important and problematic issues in ballet classes where teachers work with musicians, and then describe how I tried to approach the subject with trainee ballet teachers in the light of ideas of meter as a form of virtual gravitational field from Hatten (2004) and Larson (2012). I explain how the limited success of this project was due partly to an issue that is marginal in Hatten's narrative, but central to my students' experience of music and movement. In my discussion, I explain how my thinking about empathy in relation to these issues has developed from a concern with how music and dance are similar, to how they are different, and the implications this has for the way greater interdisciplinary understanding might be achieved.

From here onward, to save repetition of the word "ballet," whenever I use the term "teacher," "dancer," or "accompanist," I mean "ballet teacher," "ballet dancer," and "ballet accompanist" respectively. By "student teachers," I mean mainly undergraduate-level students of ballet teaching that I have taught in formal settings. However, the issues I describe are a common topic in informal discussions with dancers, choreographers or teachers of any age, experience and educational level. The problems arise continually in encounters between music, movement and notational concepts: they are not eradicated by training or 
experience. When I use the terms "meter" and "time signature" together, it is to reflect the fact that ballet teachers create exercises that are "in 3" or "in 4" without necessarily specifying a time signature. Similarly, if they do specify " $3 / 4$ " or " $2 / 4$," this does not mean that the pianist may not play something written in $6 / 8$ or $4 / 8$, as long as the music is either basically triple or duple.

\section{Musical Aspects of a Ballet Class}

In classes where a pianist is present, teacher and musician work together in a semi-improvisational way to create exercises for a group of ballet dancers or students. Classes to recorded music, or where the music has been prescribed in advance - such as for an examination or assessment - are a different matter altogether, and not my concern here, since in these classes, there is no burden on the teacher to communicate about music. Most teachers outside the vocational training and professional dance sectors use recorded music for classes, but learning to work with musicians usually forms part of the training of ballet teachers regardless of whether they will do so later, so some grounding in the rudiments of music is provided, often by one of the musicians already employed to accompany classes.

In full-time vocational training or at professional level, a class lasts on average an hour and a half, during which a teacher devises a series of about 20 exercises of perhaps 32 or 64 bars in length, that comprise ballet steps and movements appropriate to the skill-level of participants. She may have prepared these in advance and memorized them, or created them during the class. The nearest equivalent in musical practice is the vocal warm-ups given to singers before a choir rehearsal, though ballet exercises are longer and more complex. The teacher first "marks" the exercise, that is, she announces its content and structure to the dancers in an abbreviated form. In a professional-level class, two minutes of real-time exercise might be reduced to just a few seconds of ballet terminology and physical demonstration, with quick hand gestures signifying larger, slower movements, and "counts" indicating what should happen when and for how long. By convention, exercises and their music in ballet classes are almost invariably constructed in multiples of eight-count phrases. An experienced ballet accompanist can pick up from this minimal description what is required musically, especially if they have worked with the same teacher many times.[1] With less experienced musicians, it is vital for teachers to be able to describe what kind of music they want in terms of meter and tempo. Specifying length is less critical, since the teacher can always just warn the musician to stop playing when the exercise is about to end.

\section{The Problem with Time Signature: Meter, Subdivision, and Movement}

Many ballet teachers get by very well without referring to time signatures by using their voice to convey the rhythm and meter of an exercise, but they cannot avoid the topic altogether. Musicians and other teachers refer to them, and they are used in dance examination syllabi and class outlines, as well as in notation systems such as Labanotation or Benesh Movement Notation. Track listings on specialist albums of music for ballet classes often include a classification by time signature, for example "Battements glissés: 6/8" or "Pirouettes: 3/4." Those who train ballet teachers in formal or informal settings will pass on terminology and conventions from their own training, saying for example that they prefer $3 / 4$ for this kind of movement, or $4 / 4$ for that. Pianists may ask the teacher to describe the kind of music they need, and their first question might be: "What time signature do you want?" Thus in ballet training and education, time signatures exist "in the wild," alienated from their notational context, and picking up new and sometimes misleading or irrational meanings as a result. For example, some teachers will insist on students being able to recognize the "difference between $6 / 8$ and $3 / 4$," even though there are many cases where they are indistinguishable. If nothing else, natural curiosity leads teachers and dancers to want to know why this is called a $3 / 4$, and that is a $6 / 8$, and what the difference is between a $2 / 4$ and a $4 / 4$, and so on.

Such questions prove difficult to answer except in a way that would confuse the student even further. For someone moving, a change of time signature from $2 / 4$ to $4 / 4$ or $12 / 8$, or from $3 / 4$ to $6 / 8$ might make little noticeable difference, since under many conditions, all that has changed is the subdivision of the same underlying beat. Some ballet exercises consist of long, slow movements of legs and arms that take several bars, and from the dancer's perspective, it is only the number of counts that is important. Whether the movement is accompanied by two bars of $4 / 4$, of $12 / 8$, or eight bars of $3 / 4$ is almost irrelevant. Similarly, for someone marching or making movements in a march-like rhythm, if the music changes from a march in 4/4 such as the Radetzky March to one in 12/8 such as Sousa's Liberty Bell, the music may have 
a different feel (that is, the sense of motion in the music changes), but they are still moving at the same speed, with the same number of steps and the same (binary) number of limbs.[2] Dancers commonly move in hypermetrical [3] relationship with the notated time signature (Jordan, 2000), and so if anything, what is difficult for them to grasp is the opposite: the existence of levels of subdivision below a reference beat level. This illuminates London's observation that there is no "essential distinction to be made between meter and so-called hypermeter," because "having several levels of metric structure present above the perceived beat is no more extraordinary than having several levels of subdivision below it" (2012, pp. 17$18)$.

Indeed, in my experience, it is the difference between duple and triple subdivision, so simple and basic to a musician, that persistently causes confusion in teaching about meter and time signature to dance teachers.[4] Even the waltz, or rather especially the waltz, that archetypical example of 3/4, and the dance form that permeates the 19th-century ballet repertoire and the ballet class, causes problems. This is why: watch people in a room where waltz music is playing, and you probably see them tilt their head or sway from side to side. You will probably do it yourself. Germans call this schunkeln, and have a category of waltz for pieces in 3/4 time that make you want to sway from side to side, the Schunkelwalzer. If you are counting at all, swaying from one side to the other is a binary motion-so where is the 3 , or the 4 of the socalled $3 / 4$ time?

I am not saying anything new here. Bengtsson (1987) drew attention to this and other anomalies in movement, hearing and notation in relation to the waltz. Nobody, he says, hears "fourths" in a $3 / 4$, and although it is so readily taken for granted that waltzes are in 3/4, three beats in a bar, we cannot know that "everybody feels (or conceptualizes) waltz rhythm movement in such a way" (p. 73). Notation and dance movement do not correspond directly: one complete movement in the waltz comprises six steps rather than three, and are often grouped together to become twelve. At a fast tempo, dancers and listeners, if they are counting at all, may well (and justifiably) count to four, "perceiving movement-carrying groups of four 'triplets', mostly without knowing anything about triplets at all" (p. 73). Although the time signature 3/4 is regarded as synonymous with the waltz, bars of $3 / 4$ in a waltz occur in hypermetric pairs, or pairs of pairs, (McKee, 2012, p. 94; van der Merwe, 2004, pp. 250-251), and indeed, some 19th-century waltzes or waltzlike pieces were notated in 6/8.[5]

Similarly, Zuckerkandl (1956) describes the mistake a "naïve listener" might make while listening to Johann Strauss's Emperor Waltz (see Figure 1). His example demonstrates exactly what often confuses dance teachers:

A naïve listener, asked to count along in time, will almost certainly count 1-2-3-4-1- etc. If he is then told that this is a waltz, and that a waltz is notoriously in three-four time, not in four-four, he will be perplexed to explain his supposed mistake. Strictly speaking, however, he did not count wrong; he merely did not count with the basic beat, as the accompaniment gives it: He counted with the melody. (p. 177)

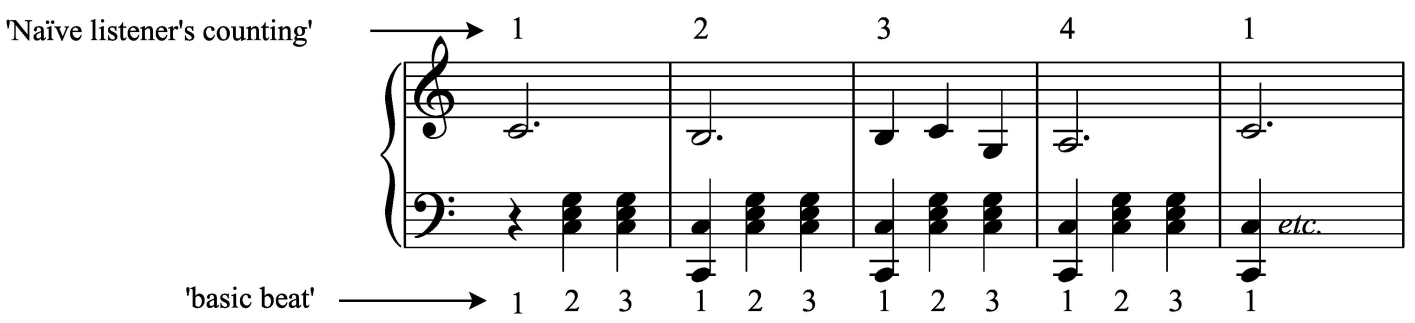

Figure 1. Counting of a "naïve listener" compared to the "basic beat" of the music, adapted from Zuckerkandl (1956, p. 177)

It is to explain such confusions that I prefer to teach student teachers about meter and hypermeter before introducing time signatures. My hope is that an understanding of meter will help to dispel such the belief, that for example, a $6 / 8$ is necessarily faster than $3 / 4$, or that a $2 / 4$ will always sound different to a $4 / 4$. Just as Zuckerkandl recruited the naïve listener's "mistaken" response in order to expose its eventual rationality 
when viewed as part of a theory of metrical hierarchy or hypermeter (without using those terms), so I use the same approach to introduce the concept of hypermeter.

I ask students to arrange themselves in rows to represent different metrical levels: one at the back who represents a sub-phrase of four bars, two in front of them represent two-bar units, then four representing bar-level, then three at beat level. A further row can be added at the front for as many eighth notes as the class size will allow, in groups of six. I encourage them to think of themselves as part of a managerial hierarchy, level 1 representing a chief executive, level 2 senior managers and so on. I play a waltz that is familiar to them such as Tchaikovsky's "Waltz of the Flowers" from The Nutcracker, and ask members of each row to make a movement or sound that marks the pulse at each respective level. I usually suggest that students toward the back (higher level) make slow arcs of the arms, and those nearer the front (middle and lower levels) make sways or claps. This enables them to experience immediately several things about meter: that it consists of multiple levels of periodicity; that the same metrical pattern can be thought of in several ways, according to which level you choose as your main beat; that a time signature such as $3 / 4$ or $6 / 8$ represents a hierarchy of beats, which may be triple at one level but duple at another.

\section{The Problem of Metrical Accent}

There is still a problem, however. To understand hypermeter, one first has to have a concept of metrical accent, and this model still does not help with that. The metrical grouping [6] is an emergent property of the coincidence of the two pulse levels. Dancers in each line represent single, accentless pulse-events in a stream that are only organized into metrical groups by the slower pulse events represented in the line behind, out of sight and out of mind. It is an interesting framework to place over music, but it does not help novice teachers with their immediate problem, which is to be able to recognize and confidently express duple and triple meter (or subdivision) as salient features of music when teaching. By "confidently express," I mean use the voice to convey a secure and accurate tempo, and indicate meter by with a sense of weight on the first beat and lightness on unaccented beats. Some teachers can do this instinctively, whether they have previous musical training or not. In trying to find ways to teach this to those who cannot, I wondered whether the upright, well-held upper body posture, stretched legs and courteous formality that are characteristic of ballet training might be inimical to the kind of bouncing, bobbing, foot-tapping and swaying that contribute to a felt sense of meter.

This was not just guesswork: there is compelling evidence to suggest that the vestibular system plays an important role in meter perception (Phillips-Silver \& Trainor, 2005, 2007, 2008; Trainor, Gao, Lei, Lehtovaara, \& Harris, 2009; Trainor, 2007). Movements such as nodding the head, bending the knees or swaying from side to side not only help listeners to entrain to a beat in music, but are also crucial for parsing or construing meter. For example, a listener will hear a stream of accentless pulses as "in two" or "in three" if she sways from side to side every two or three beats. Once the meter has been established this way, she will continue to hear it this way even if she stops swaying, similar to the phenomenon of "subjective rhythmization," or more appropriately, as Large (2008, p. 197) points out, subjective meter, whereby metrical grouping is heard in a stream of unaccented pulses-hearing the ticking of a clock as "tick tock," even though the sound comprises only a series of identical ticks, for example.

Equally compelling was Robert Hatten's theory of musical gesture as energetic shaping through time, in which he states that for Western music at least, "meter functions like a gravitational field that conditions our embodied sense of up versus down" (2004, p. 115). If we perceive motion in music, then that virtual motion (or rather, our perception of an agent in music that moves) is subject to virtual forces such as gravity:

If meter and tonality each afford analogies to gravitation, or more broadly, vectoral space, together they enhance an experience of embodied motion, in that they provide the listener with dynamics and constraints comparable to those the body experiences in a natural environment, including its orientation as up or down. (2004, p. 117)

His work seemed to bring to life-literally, through the suggestion of human motion in the musicclassical compositions that I can find cerebral and disembodied at times. In his interpretation, the two-note slur, for example, can been seen as: 
[the] musical analogue to such ritualized social gestures as bows, nods, inflections of the wrist and hand, and other aristocratic social graces...the weak-beat galant cadence captures the qualitative character of all gracious social gesturing in the eighteenth century, male and female alike. (2004, p.140)

I found the theory convincing because it resonated immediately with my own embodied experience of music, and identified for me the essence of what I would consider "unmusical" marking, that is, the absence of a connection between metrical accent and weight.

With these two aspects of meter in mind - the role of the vestibular system, and Hatten's theory of meter as a virtual gravitational field - I set out to see if I could use these ideas with students to try to learn to make connections between weight, gesture, meter, and voice. In the next section I describe a class where I tried this out. Although I call this "experimenting," I should emphasize that this was not a formally designed experiment, but an ad hoc strategy in an everyday teaching episode that turned out to raise more questions than it answered.

\section{EXPERIMENTING WITH METER, WEIGHT, AND GRAVITY IN A MUSIC CLASS FOR TRAINEE BALLET TEACHERS}

I started by playing a Strauss waltz on the piano, and asked the students first to do whatever came naturally to them. Mostly, this consisted of swaying in time to the metrical accent. Then, dividing them into groups, I asked them to think up a combination of movements that involved weight (bouncing or swaying) to suggest a downbeat, and claps, clicks, or other movements to indicate the non-accented beats of each bar. Finally, I asked them to vocalize in some way this sense of weight, pulse, and meter. The task proved moderately successful, but did not result in the kind of breakthrough of embodied understanding that I had hoped for. Some used only minimal weight, bend, or sway on the metrical accent, and others who did could not necessarily express it in their voice. Downbeats might be louder, but there was little sense of weight, or "down" in them.

I tried a different approach: perhaps dance movements might be more meaningful and accessible in this task than clicks and bounces. I asked two students who had learned ballroom dancing to teach the other students how to do a basic waltz step. Once they had taught it, the class did this all together while I played the same Strauss waltz as before on the piano. We then did the same with different music and dance steps: polonaise steps to polonaises, and mazurka steps to mazurkas, looking for evidence of gravity, for the "embodied sense of up versus down."

In the group discussion that followed, a fundamental detail of the students' experience emerged that that contradicted my idea of a gravitational pull towards a metrical accent: the ups and downs in their steps did not correlate with upbeats and downbeats in the music. In the basic "box step" from the waltz that my students demonstrated, for example, the first beat consisted of a step backwards with the right foot on a bent knee, the second a low rise onto the balls of the feet while the left foot steps out to the left, and the third, a closing of the right foot to the left and a lowering of the heels (so that the "upbeat" to the next one is accompanied by a downward sink). It is difficult to say that any of this happens on a beat, or is up or down, because there is a continuous back-side-together motion on the horizontal plane, and a continuous fall-rise-fall through the bar on the vertical plane, like the fairground ride called, appropriately, a "waltzer," on which cars, rotating on their own axes, circulate on an undulating track. In a waltz with a partner (it is after all, a couple dance), other feelings of motion may come into play such as being off-balance, leading, driving, retreating, being caught.[7] As I observed it, and as the students themselves remarked, if there is any sense of "accent," it is in the middle of the bar, as the body rises. The sink on the next musically strong beat is prepared by that rise, it is not a downward movement in isolation: what goes up must come down, and similarly, what goes down, must have gone up first. A similar contradiction was evident in the polonaise step as demonstrated by the students. The step on "one" - that is, the first beat of the barconsisted, as one student put it of a "step upward with purpose" (the others agreed with this interpretation too), and the sink downwards was on the third beat of the bar. The mazurka step, though it had a sink on the first beat, held so many other choreographic challenges that this downward motion seemed more like a carefully executed component of the step as a whole, rather than giving in to gravity. In both the mazurka and polonaise, there is also a strong sense of forward motion. Hatten does in fact acknowledge such contradictions in a footnote: 
[t]he metric orientation up versus down does not always map in the most obvious ways onto culturally conventionalized dance steps. Little and Jenne (1991:21) note that in the noble French style of Baroque dance, the plié (or "sink", in English) - a downward motion involving bending of the knees - is performed on the upbeat of the music, whereas the elevé-an upward motion to the balls of the feet-is performed on the downbeat. (Hatten, 2004, p. 304)

\section{Meter and the Trained Body}

However, while such a contradiction is just a footnote in Hatten's discussion, "conventionalized dance steps" are what my students have specialized in since childhood. Hatten's assertions about meter and gravity seem instinctively correct to $m e$, but they may not seem so to dancers who have spent many years training their bodies to move to music in highly skilled, but not necessarily simple or obvious ways, until they become second nature through continual practice. They have learned to dance the baroque minuet, the polonaise, the waltz, and other dances where downward movements do not necessarily coincide with metrical accents.

Hatten implies that the most obvious way for steps and music to relate is that that downward steps should go with downbeats, but it is not clear how this association should have come about. Why is it the obvious way? Although the construction of the theory of gesture is robust and convincing, we nonetheless have to take for granted as a premise that "the dynamic environment in which we experience our bodies and their gestures has its virtual counterpart in music" (p. 115). This virtual field is just "there" as an entailment of the theory of motion in music, and with it, unexplained, as far as I can see, the idea that it is natural to associate downward motion (or resting) with metrical accents. A similar premise is evident in Steve Larson's theory of rhythmic gravity: "the terms 'downbeat' and 'upbeat' reflect the simplest ways in which dance-like motions associate downward physical motions with musical motions towards metrically stable points....In the domain of meter, 'down' beats are moments of greater metric stability" (Larson, 2012, pp. 148-149).[8]

Musicians might find it strange to associate downbeats with upward motion, but then their bodies do not always move in natural or obvious ways either. Given that my students and I have both taken part in rigorous, long-term physical training of different types, is there any reason why I should regard my embodied sense of motion in music as any more real, instinctive, spontaneous, or "musical" than theirs? [9] The body that $I$ bring to music has undergone years of physical training, learning to sit at a piano and associate downbeats with downward motions of the arms that are no more natural than a dancer's arabesque, insofar as they have to be learned and practiced until they become automatic. If I nod my head or tap my foot to music, can I ever tell conclusively whether this is something that I "naturally" do, or if it as a result of my experience as a musician and the kind of movements that I have made while playing and learning to play?

So while I am convinced that our understanding of music is in some way grounded in bodily experience (indeed, what else could it be grounded in?), I am also persuaded from experience of working with dancers that different bodies, different regimes of physical training, different bodily stances while listening (whether sitting, walking, dancing), even different clothing, can lead to different hearings of the same music (see Maes, Leman, Palmer, \& Wanderley, 2014, for a recent summary of research in this field). Larson (2012) allows for such differences in his discussion of how listeners parse pulses into meter: the fact that people group beats in different ways "underscores the point that it is our minds, not just the stimuli, that shape the meaning that is created" (p. 137). He is clear that the "hearing as" of different listeners will vary according to their experience and context. He also warns that although sensations of flow, motion, and forces are not inherent in the music, even though they tend to be experienced as such: they are "created in the mind of the listener, who then attributes them to the music" (p. 137). In a footnote, he says further that whenever he speaks of musical forces, the reader "should understand that I am speaking not of tendencies literally present in the music as stimulus, but of tendencies attributed by the minds of experienced listeners (who experience the music as if it were literally subject to such forces" (Larson, 2012, pp. 337-338).

This is similar, though not entirely equivalent, to the point that Green makes about the difficulty of distinguishing, except theoretically, between two types of musical meaning that she categorizes as either "inherent" (or "inter-sonic") or "delineated" (Green 2005, 2008, pp. 87-91). Inherent or inter-sonic meanings are those that are proper to the conventions of a musical style, and are only construed as meaningful if the listener is competent in that style through enculturation or learning. Delineated meanings 
are those that are strongly associated with the music, but point to things external to the musical sounds and structures. DeNora draws on this distinction to develop a theory of how music affords and enables action: "Music comes to afford things when it is perceived as incorporating into itself and/or its performance some property of the extra-musical, so as to be perceived as 'doing' the thing to which it points" (DeNora, 2003, p. 57). As an example, a piece of music in 3/4 time can only be heard as "a waltz" by someone who is familiar with that dance form. If they have danced the waltz, they may attribute motional qualities to the music that they feel make them want to waltz, but at least some of these qualities have been inferred by the listener by association with things outside the musical sound.

It is in this problematic space where it is difficult to determine whether we are simply "hearing" or "hearing as," that meter is located. London (2012, p. 18) describes the nature and origin of metrical accent as a "perennial bugbear of music-theoretical accounts of meter." His own theory of meter as a form of entrainment places "the accentual burden on the entrained listener rather than on the music" (p. 18). This is not to say that there are no accents phenomenally present in the music, but that metric patterns do not depend on metric accent (in the sounding music) in order to be perceived as such and continued in the mind of the listener. Iyer (1998) likewise states that the best understanding of meter is "as a cognitive/perceptual phenomenon, not as an objective reality of the acoustic signal. However, this distinction is often elided, so we might speak of the meter of a piece of music." In a particularly remarkable example, Agawu (2006, pp. 23-24) explains how a knowledge of the way that the feet move in Southern Ewe dances can fundamentally alter the way that the "Standard Pattern" of West African rhythm is understood and transcribed, changing what has often been notated and theorized as an additive meter, to a divisive one. Meter is established for dancers and musicians alike by the physical or imagined presence of the dancing body. It "cannot (always) be inferred from the sounding forms alone. One brings a metric attitude-perhaps even a metric prejudice - to the performance" (2006, p. 23). This metric attitude, Agawu continues, is no different to the conventional understandings that an enculturated listener brings to tonal music, in which harmonic changes are heard as tensions and resolutions, for example. What listeners hear "in" the music are not all immanent properties of the works, "some are perspectives formed from certain ways of world-making" (2006, p. 24).

In the kind of basic music theory that is taught to dance teachers, however, meter is often presented as if it were a property of the music, that is, that there is, or should be, a pattern of weak and strong beats objectively observable in the musical signal that will enable the student to calculate and deliver up the correct time signature to the teacher in a test. Musical examples used for such tests have to be metrically unambiguous either by design or performance to make the task possible.[10]

\section{Alternatives to Meter: Vitality Forms and the Digital and Analogue in Music And Dance}

When I originally began this article as a paper for the student day at the SEMPRE conference on Music and Empathy in 2013, I concluded that Daniel Stern's (2010) concept of vitality forms was a much more appropriate starting place to consider relations between music and dance than meter, given the problems I have outlined above. Stern uses the term "dynamic forms of vitality" to describe the supramodal or amodal "how" of an action rather than its content. These vitality forms, which combine ideas of "force, movement, space, directionality and aliveness" as well as time and intensity (2010, p. 17) are crucial, in his view, to affect attunement, one of the processes involved in empathy. For example, a mother might match an infant's excited facial expression with an expression of excitement in another modality such as sound. It differs from imitation, where the content of an action is mirrored or copied, but reflects instead "the mother's attempt to share the infant's subjective experience." By choosing her own modality and content, the mother "assures the baby that she understood, within herself, what it felt like to do what he did" (p. 114). This capacity for attunement in different modalities is what makes vitality forms, in Stern's view, the "Esperanto" (p. 21) that enables communication and collaboration between art forms.

This highlights the affective, gestural aspects of music, dance, and communication that are not captured by meter, counting, or time signature. Without vitality forms, Stern says, human interactions would be "digital rather than analogic" (p. 4), which seems to echo Lefebvre's criticism of a tendency to attribute mechanical overtones to rhythms, ignoring the "organic aspect of rhythmed movements." Musicians, as producers of rhythms, "often reduce them to the counting of beats [des mesures]: 'One-twothree-one-two-three"'(Lefebvre, 2004, p. 6). This describes well the common situation where ballet teachers tell accompanists that they want "a 3/4" or "a $2 / 4$," or mark an exercise with deadpan counts, without communicating anything about the dynamic qualities of the movement, or what it feels like to do it.[11] As a result, novice accompanists often fail to understand the intention of the exercise, or the effort 
involved, and choose inappropriate music as a result. Guest (1983, pp. 8-9) identifies another analogdigital distinction between music and dance: in contrast to music where pitches can "jump" in intervals, all movement is "chromatic," that is, it is impossible for parts of a body to move from one position to another without traversing the space in between, even if fast, jerkily performed movements appear to do so to a spectator.[12] What attracted me to Stern's theory was that vitality forms seemed to offer an immediate, intuitive way to see connections and commonalities between music and dance that are obscured, misrepresented, or left out altogether by meter and time signature.

\section{From Vitality Forms to Perspective Taking}

On further reflection, however, I realized that these same tensions are already inherent in the opposition between "time-discrete" and "time-continuous" accounts of meter (London, 2012, pp. 19-20, 79-81), and in the disparity between the discrete nature of music notation compared to the continuities of sound and musical gesture referred to by Hatten (2004, p.113) and Spitzer (2004, p. 89). More broadly, they reflect the difference between what Hamilton (2007, p. 119) calls "abstract and humane conceptions of music," such as the Pythagorean concept of music as number as opposed to a "felt conception of music" (see also McClary, 1995). These tensions could thus be acknowledged in the teaching of music, meter, and notation without needing to import the concept of empathy or vitality forms. Moreover, the idea of vitality forms as immediately recognizable, amodal gestalts is at odds with the observations I have already made with regard to metrical accent and gravity in dance forms, where dialogue and listening to the dancers' perspective was necessary in order to understand why their feelings about meter (if indeed they had any at all), might be different to mine.

I now think that as far as meter is concerned, it might be more productive to explore the ways in which dance and music are not like each other, than to start all over again (with vitality affects) by looking at other respects in which they are. The empathic process is still implied here, but it is the otherness of dance and music that is emphasized, which places a greater focus on perspective taking than on affect attunement. Although it is common to believe that music and dance are genetically related as sister arts, or that dance is an interpretative response to music, or that rhythm is common to both art forms, such views can lead a musician to assume that they know more about dance and dancers than they do.[13] There are also limits to how much one can talk about dance using the terminology of music without sacrificing conceptual clarity or the particularity of each art form, as McMains and Thomas (2013) have pointed out. I would go a step further than they do, however, and suggest that meter has too many entailments as a musical concept to be applied to dance as a third-party structural device that fits music and dance equally. Does rhythm really offer "a clear point of translation across the mediums" (p. 202) as they maintain?

For example, perhaps the reason that teachers do not always invest their counts with metrical weight is because dancers' counts are not always the conceptual equivalent of beats in a bar. Firstly, they often function more like bar numbers than beats in a bar or a hypermeasure. Like bar numbers, they are the equivalent of addresses or locations on a map, they do not have to function as part of a metrical script (see Guest, 2005, pp. 37-38). Secondly, some teachers count while music is playing as a means of marking pulses, but they could as easily use any words or sounds to do this: the numbers between 1 and 8 do not have any metrical significance in this context, they are simply "counting along." Thirdly, they can occasionally be a way counting up steps rather than counting beats, rather like the numbers in the lyrics of the children's song "One, two, three, four, five, once I caught a fish alive."

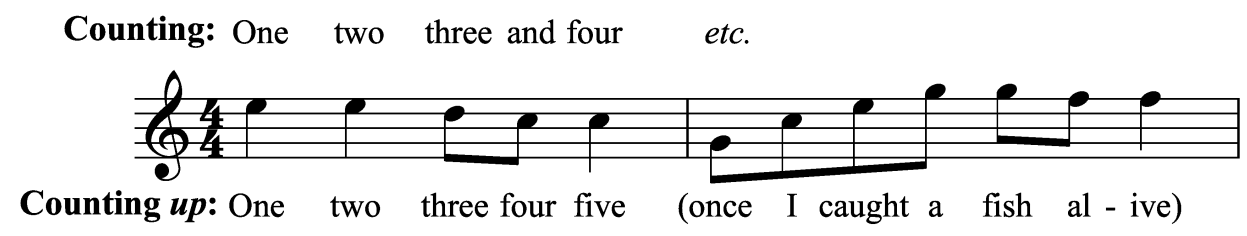

Figure 2. The children's song "One, two, three, four, five, once I caught a fish alive." The "counting up" numbers in the song do not have the same meaning or position as the counting of beats in a bar.

Jeanne Bamberger has discussed a similar phenomenon in her research into children's visual representations of rhythm. Analyzing their drawings, she recognized two persistent categories of hearing 
and counting, one that she calls metric, the other figural (or motivic), related to the concepts of meter and grouping in Lerdahl and Jackendoff (1983). She elaborates on the distinctions between these two kinds of hearing by inventing imaginary students, Met and Mot (standing for "metric-" and "motivic-" oriented hearers) who use counts in different ways. Met sees counts as something that remain the same, units that can be used to measure; Mot uses counts to "count-up," to gather events into a figure, regardless of their temporal relationship. She concludes that counting - at any age - is not simply a "neutral and 'objective' act," but varies according to what a listener considers an object to be counted in the first place (1991, p. 273). This careful nuancing of counting and numbers coincidentally resonates with an observation by Wittgenstein about negation, and the effect of framing questions: if you are asked: "Do you mean the same by both 'ones"?" in the sentence " 1 metre is occupied by 1 soldier, and so 2 metres are occupied by 2 soldiers," your answer will be perhaps: "Of course I mean the same: one!" However, if the question is framed as "has ' 1 ' a different meaning when it stands for a measure and when it stands for a number?" your answer will be the opposite: that it does have a different meaning (2009, p. 156). "One," it turns out, is not a singular sensation.

\section{CONCLUSION}

Teaching about meter to dancers who have little or previous musical training is difficult because, to use the language of music perception researchers, they would be categorized as "naïve," "unskilled," or "inexperienced" listeners, or "non-musicians" (see London, 2012, p. 172 for a discussion of this point). Yet in many ways they are not musically naïve or inexperienced at all. They may work closely with music for several hours daily, and in some respects, their skills can exceed those of the average musician. For example, a dancer might understand nothing about time signature, yet have memorized the whole of Stravinsky's Rite of Spring, and be able to perform complex choreography to it with faultless precision and rhythmic accuracy. She may know more than one version of it, as well as holding other several other pieces of repertoire in memory at the same time.

I have suggested that the problems I have encountered with teaching meter to dancers is not because their hearing of music is necessarily naïve or inexperienced, but as a result of their physical training and the sensations caused by moving to music, rather than sitting and listening to it. Musicians' hearing may also be conditioned by their training and engagement with musical instruments, and by topdown biases acquired by knowledge of how music has been notated. My skepticism about the relationship between downbeat, weight, and gravity in the theories of Hatten and Larson is therefore not intended as a critique of their work, but as a form of self-criticism, or as Mead (1999) and Cusick (1994) put it, an admission of a "shock of recognition" about the role of the body in hearing music, the shock being that I had construed the "weight" that I felt in music as belonging to the musical sound, rather than my experience of it, and thus found it difficult to understand why others might not feel it there. In this sense, movement-based approaches to musical understanding such as Dalcroze classes, or the work of Alexandra Pierce (Hatten, 2004, pp. 126-131; Pierce, 1994, 2007; Spitzer, 2004, pp. 89-91) may be seen as useful choreographic exercises that can bring a sense of weight or gravity to the music through the body, but they do not discover it there.[14]

I like Agawu's suggestion that we bring a metrical prejudice to hearing music. It conveys a sense of the problems I have just described, and it points towards a certain imbalance in disciplinary power relations between practitioners of music and dance. By this I mean that if musicians regard dancers as naïve listeners, they may discredit what they see as dancers' illegitimate hearings of music, unaware of the prejudice they themselves bring to music perception as a result of their training. In turn, this reminds me of Miranda Fricker's concepts of testimonial and hermeneutical injustice (2007). Testimonial injustice occurs when a witness's testimony is disregarded or discredited due to prejudice against their perceived social identity. Hermeneutical injustice occurs when there are "blanks where there should be a name for an experience which it is in the interests of the subject to be able to render communicatively intelligible" (p. 160). Individual cases may not meet the criteria for injustice, but be deemed rather as "epistemic bad luck" or "disadvantage." However, if a particular hearing of music (as in Zuckerkandl's example of Strauss" Emperor Waltz) is rejected as wrong in a test, and the student not only fails the test, but also believes thereafter that she has been proven "unmusical," then this seems to me a form of injustice.

If it seems too dramatic a leap from the notion of prejudice in Agawu's sense to epistemic injustice in Fricker's, then let me put it another way: that in the realm of meter, musicians are particularly prone to the "curse of knowledge," that is, the inability to imagine what it is like to be naïve about 
something that we already know (Birch \& Bloom, 2007; Camerer, Loewenstein, \& Weber, 1989). We cannot necessarily know or imagine what it is like to hear like someone else, or to move like them, but it is perhaps even harder to un-know what we know, to unhear music in the way that we have already heard it. In the texts I have cited, Bengtsson, Zuckerkandl and Bamberger have managed to lift the curse, so to speak, and listen empathically to how others hear music, and give epistemic value to their testimony. Our sense of motion in music may be constrained by our own training, what we can do, or have experienced, or can imagine doing, or the kinds of movement that we feel the music "invites us" to do. If that is the case, then watching dance gives us the opportunity to re-hear music, alerting us to things that we might hardly notice otherwise (Jordan, 2011). This extends even to what might usually be considered structural analysis: Agawu (2006) makes a strong case for the importance of understanding dance as a contribution to music analysis. Dancing an 18th-century minuet, for example, encourages different perceptions of the meaning of a repeat in the music, either as a return back on the same pathway, or-if the floor-pattern is S- or Zshaped - as a linear form, not the large-scale repetition that a score-based understanding would elicit.

The same applies to the perception of meter, though I am not advocating an "anything goes" approach. Collaboration demands shared understandings and conventions, and if meter can mean anything we want it to, it is no help to anyone. I am suggesting, rather, as Clarke puts it in Ways of Listening, there is a middle path to be forged between interpretation and empirical approaches that "combines interpretation with the attempt to ground the analysis in perceptual principles" (2005, p. 123).

One difficulty that I raise here as a final question, is that if we agree that the body has a role to play in the cognition and interpretation of music (Agawu, 2006; Hatten, 2004), then how do we account for that in an analysis that is grounded in perceptual principles? What kind of movement is the analyst permitted to make while analyzing? Is there something about music analysis or empirical studies of music perception that demands that either the subject or the analyst is sedentary and immobile, as Biddle (2011) has said in his critique of "fixated" or "disciplinary" listening? Should she sit or stand? Should she tap her fingers or her feet, sit, sway, or just "move along" to music (Leman, 2008)? Or may she also dance?

\section{NOTES}

[1] For a good example of this process, see the Royal Ballet's live-streamed ballet class (Royal Opera House, 2012).

[2] Some steps, such as a waltz or mazurka are triple by nature, and the meter of the music must reflect this in order for step and music to synchronize with one another. I have used duple examples because they illustrate the issue more clearly.

[3] I am using the term "hypermeter" somewhat irresponsibly here as a kind of shorthand to make a general point about the relationships between levels of the beat in music and its notation, and the movement of a human body in relation to these. However, I am aware, as Smyth (1992) has explained, that this stretches the meaning of hypermeter in a way which dilutes the original concept. It would be valuable to discuss the implications of Smyth's article for dance analysis, but here is not the place.

[4] In this respect, the notion of triplierte Taktarten [meters of tripled beats, or tripled meters] of Kirnberger and Koch discussed by Mirka (2009, p. 10), where a piece in 2/4 or 3/4 with triplet motion is written as $6 / 8$ or $9 / 8$ from notational necessity, even though it is 2 or 3 that is felt as the main beat, would help non-musicians to distinguish between these and "real" $6 / 8 \mathrm{~s}$ or $9 / 8 \mathrm{~s}$, where the eighth-note motion is more prominent. This is an example of how questions of meter that are historically and conceptually complex are oversimplified when they are taught in "rudimentary" ways, whereas, in my view, the more complex explanation is easier to understand because it is rational.

[5] Many of the well-known 19th-century ballet solos that dancers would regard as "waltzes" are written in 6/8. The interpolated male solo in Tchaikovsky's Swan Lake (No. 19a, Variation 1) is written in 6/8, but is a canonical example of what many listeners would parse as $3 / 4$, and what most ballet teachers would call a "big waltz."

[6] In relation to Lerdahl and Jackendoff's differentiation between grouping and meter, there is a terminological problem here because meter also involves grouping (see Mirka, 2008, p. 14 [footnote 24]). 
Here, I mean the grouping of beats into a metrical structure, though when I refer to Bamberger (1991) later, the differentiation in Lerdahl and Jackendoff's sense becomes important.

[7] From a conversation with the choreographer Kate Flatt: "In the first part of [i.e. bar 1] it the man is leading and driving, and the girl is retreating, in the second part of it [bar 2] she's caught, and carried on round...So she's retreating, leading him, he catches her." Kate's view was that the rhythm of a Viennese waltz for her was a "heartbeat," not three counts.

[8] Although Hatten and Larson's theories have much in common, I perceive a crucial difference in them with respect to metaphor. Briefly, Hatten is interested in first capturing the prelinguistic and preconceptual aspects of gesture in any modality (2004), preferring the term "intermodality" to describe the integration or interaction between perceptual sources in different sensory modalities, to the term "metaphor" used in Lakoff and Johnson's theory of cross-domain mapping. See also Lakoff \& Johnson's own discussion of the "metaphor of metaphor" in their afterword to the 2003 edition of Metaphors we live by (2003, pp. 252264). By contrast, in "Something in the way she moves," the chapter of Musical Forces co-authored with Mark Johnson (2012, pp. 61-81), Larson writes that "our thinking in music-our very experience of musical meaning - is fundamentally shaped by conceptual metaphors that are grounded in our bodily experience" (p. 78). The distinction seems important to me, but this would entail an entirely different discussion for which there is no room here.

[9] I am talking specifically here about the way that dancers perceive music while in a dance studio, with their mind in "dancer mode." There are undoubtedly many situations where dancers listen to music with a different kind of attention.

[10] Cook (2013, p. 93) refers to an experiment in which one pianist made a much clearer disambiguation of an ambiguous metrical pattern than other musicians. It was later revealed that this person had also recorded dictation tests for examination boards. I have heard (and also performed) similar manipulations of musical material in order to get a metrical point across, hammering out a rhythm in order to make it clear that music is in $3 / 4$, even though this is not how music is performed anywhere except the classroom (as Cook says, "The didactic context elicits a particular style of playing").

[11] It is ironic that while musicians blame dancers for reducing music to counts (as I am doing here), if Lefebvre is right, then perhaps they have learned to do this from musicians.

[12] In the context of a book on movement notation, as this is, the distinction is useful. However, from a music-phenomenological perspective, there is more to it than that: Clifton (1983) interprets the "primary phenomenon" of a leap of a $10^{\text {th }}$ in Beethoven's Grosse Fugue, Op. 133 not as intervallic, but as "gestural, with $\mathrm{d}^{1}$ and $\mathrm{f}^{2}$ marking the beginning and terminal points of a vigorous, upswinging gesture" (pp. 21-22). It is also important to acknowledge that the movements needed to perform intervals on an instrument are still in themselves "chromatic" even though the notes produced "leap" by interval.

[13] The opposite could in theory also apply, but it rarely does, in my experience. Also, in the context of a music class, it seems more likely that the dance student will assume they know less about music than they do.

[14] For reasons of space, I have not pursued an important related point made by Spitzer (2004) that we can learn to hear music as anything, and by Adlington (2003) that there are other, equally valid non-motional metaphors for hearing change in music such as "brightening" or "softening."

\section{REFERENCES}

Adlington, R. (2003). Moving beyond motion: Metaphors for changing sound. Journal of the Royal Musical Association, 128(2), 297-318. doi:10.1093/jrma/128.2.297

Agawu, K. (2006). Structural analysis or cultural analysis? Competing perspectives on the "standard pattern" of West African rhythm. Journal of the American Musicological Society, 59(1), 1-46. 
Bamberger, J. (1991). The mind behind the musical ear. Cambridge, Mass: Harvard University Press.

Bengtsson, I. (1987). Notation, motion and perception: Some aspects of musical rhythm. In A. Gabrielsson (Ed.), Action and perception in rhythm and music (Vol. 55, pp. 69-80). Stockholm: Publications issued by the Royal Swedish Academy of Music.

Biddle, I. D. (2011). Listening, consciousness, and the charm of the universal: What it feels like for a Lacanian. In D. Clarke \& E. Clarke (Eds.), Music and consciousness: Philosophical, psychological and cultural perspectives (pp. 65-77). Oxford: Oxford University Press.

Birch, S. A. J., \& Bloom, P. (2007). The curse of knowledge in reasoning about false beliefs. Psychological Science, 18(5), 382-386. doi:10.1111/j.1467-9280.2007.01909.x

Camerer, C., Loewenstein, G., \& Weber, M. (1989). The curse of knowledge in economic settings: An experimental analysis. Journal of Political Economy, 97(5), 1232-1254.

Clarke, E. (2005). Ways of listening an ecological approach to the perception of musical meaning. New York: Oxford University Press.

Clifton, T. (1983). Music as heard: A study in applied phenomenology. New Haven: Yale University Press.

Cook, N. (2013). Beyond the score: Music as performance. New York: Oxford University Press.

Cox, A. (2011). Embodying music: Principles of the mimetic hypothesis. Music Theory Online, 17(2). Retrieved from http://www.mtosmt.org/issues/mto.11.17.2/mto.11.17.2.cox.html

Cusick, S. G. (1994). On a lesbian relationship with music: A serious effort not to think straight. In P. Brett, G. C. Thomas, \& E. Wood (Eds.), Queering the pitch: The new gay and lesbian musicology. New York: Routledge.

DeNora, T. (2003). After Adorno: Rethinking music sociology. Cambridge: Cambridge University Press.

Eitan, Z., \& Granot, R. Y. (2006). How music moves. Music Perception, 23(3), 221-248. doi:10.1525/mp.2006.23.3.221

Fricker, M. (2007). Epistemic injustice: Power and the ethics of knowing. Oxford; New York: Oxford University Press.

Green, L. (2005). Meaning, autonomy and authenticity in the music classroom. London: Institute of Education.

Green, L. (2008). Music, informal learning and the school: A new classroom pedagogy. Aldershot: Ashgate Publishing Ltd.

Guest, A. H. (1983). Your move: A new approach to the study of movement and dance. New York: Gordon and Breach.

Guest, A. H. (2005). Labanotation: The system of analyzing and recording movement (4th ed., rev.). New York: Routledge.

Hamilton, A. (2007). Aesthetics and music. London: Continuum.

Hasty, C. F. (1997). Meter as rhythm. New York; Oxford: Oxford University Press. 
Hatten, R. S. (2004). Interpreting musical gestures, topics, and tropes: Mozart, Beethoven, Schubert. Bloomington and Indianapolis: Indiana University Press.

Houle, G. (1987). Meter in music, 1600-1800: Performance, perception, and notation. Bloomington: Indiana University Press.

Iyer, V. (1998). Microstructures of feel, macrostructures of sound: Embodied cognition in West African and African American musics (Doctoral thesis). University of California, Berkeley,. Retrieved from http://archive.cnmat.berkeley.edu/People/Vijay/05.\%20On\%20meter\%20perception.html\#anchor240453

Iyer, V. (2002). Embodied mind, situated cognition, and expressive microtiming in African-American music. Music Perception, 19(3), 387-414.

Jordan, S. (2000). Moving music: Dialogues with music in twentieth-century ballet. London: Dance Books.

Jordan, S. (2011). Choreomusical conversations: Facing a double challenge. Dance Research Journal, 43(1), 43-64.

Lakoff, G., \& Johnson, M. (2003). Metaphors we live by. Chicago: University of Chicago Press.

Large, E. E. (2008). Resonating to musical rhythm: Theory and experiment. In S. Grondin (Ed.), Psychology of Time (pp. 189-231). Oxford: Elsevier Science.

Larson, S. (2012). Musical forces: Motion, metaphor and meaning in music. Bloomington \& Indianapolis: Indiana University Press.

Lefebvre, H. (2004). Rhythmanalysis: Space, time, and everyday life. London; New York: Continuum.

Leman, M. (2008). Embodied music cognition and mediation technology. Cambridge, Massachusetts; London, England: The MIT Press.

Lerdahl, F., \& Jackendoff, R. (1983). A generative theory of tonal music. Cambridge, Mass.; London: MIT Press.

Little, M., \& Jenne, N. (1991). Dance and the music of J.S. Bach. Bloomington: Indiana University Press.

London, J. (2012). Hearing in time: Psychological aspects of musical meter (2nd ed.). New York: Oxford University Press.

Maes, P.-J., Leman, M., Palmer, C., \& Wanderley, M. (2014). Action-based effects on music perception. Theoretical and Philosophical Psychology, 4, 1008. doi:10.3389/fpsyg.2013.01008

McClary, S. (1995). Music, the Pythagoreans and the body. In S. L. Foster (Ed.), Choreographing history (pp. 82-104). Bloomington \& Indianapolis: Indiana University Press.

McKee, E. (2012). Decorum of the minuet, delirium of the waltz: A study of dance-music relations in 3/4 time. Bloomington: Indiana University Press.

McMains, J., \& Thomas, B. (2013). Translating from pitch to plié: Music theory for dance scholars and close movement analysis for music scholars. Dance Chronicle, 36(2), 196-217. doi:10.1080/01472526.2013.792714

Mead, A. (1999). Bodily hearing: Physiological metaphors and musical understanding. Journal of Music Theory, 43(1), 1-19. doi:10.1215/00222909-43-1-1 
Mirka, D. (2009). Metric manipulations in Haydn and Mozart: Chamber music for strings, 1787-1791. Oxford: Oxford University Press.

Phillips-Silver, J., \& Trainor, L. J. (2005). Feeling the beat: Movement influences infant rhythm perception. Science, 308(5727), 1430.

Phillips-Silver, J., \& Trainor, L. J. (2007). Hearing what the body feels: Auditory encoding of rhythmic movement. Cognition, 105(3), 533-546. doi:10.1016/j.cognition.2006.11.006

Phillips-Silver, J., \& Trainor, L. J. (2008). Vestibular influence on auditory metrical interpretation. Brain and Cognition, 67, 94-102.

Pierce, A. (1994). Developing Schenkerian hearing and performing. Intégral, 8, 51-123.

Pierce, A. (2007). Deepening musical performance through movement: The theory and practice of embodied interpretation. Bloomington: Indiana University Press.

Rothstein, W. (2008). National metrical types in music of the eighteenth and early nineteenth centuries. In D. Mirka \& K. Agawu (Eds.), Communication in eighteenth-century music (pp. 112-159). Cambridge UK; New York: Cambridge University Press.

Royal Opera House. (2012). Royal Ballet Daily Class (complete video) Royal Ballet LIVE. Retrieved from $\mathrm{http}: / / \mathrm{www}$. youtube.com/watch?v=5EVMjnHFg-w\&feature=youtube_gdata_player

Smyth, D. (1992). Patterning beyond hypermeter. College Music Symposium, 32, 79-98.

Spitzer, M. (2004). Metaphor and musical thought. Chicago: University of Chicago Press.

Stern, D. (2010). Forms of vitality: Exploring dynamic experience in psychology, the arts, psychotherapy, and development. Oxford: Oxford University Press.

Toiviainen, P., Luck, G., \& Thompson, M. R. (2010). Embodied meter: Hierarchical Eigenmodes in musicinduced movement. Music Perception: An Interdisciplinary Journal, 28(1), 59-70.

Trainor, L. J. (2007). Do preferred beat rate and entrainment to the beat have a common origin in movement? Empirical Musicology Review, 2, 17-20.

Trainor, L. J., Gao, X., Lei, J., Lehtovaara, K., \& Harris, L. R. (2009). The primal role of the vestibular system in determining musical rhythm. Cortex, 45(1), 35-43.

Van der Merwe, P. (2004). Roots of the classical: The popular origins of Western music. Oxford: Oxford University Press.

Wittgenstein, L. (2009). Philosophische Untersuchungen = Philosophical investigations (Rev. 4th ed.). Chichester, West Sussex, U.K.; Malden, MA: Wiley-Blackwell.

Zuckerkandl, V. (1956). Sound and symbol. Princeton, N.J.: Princeton University Press. 